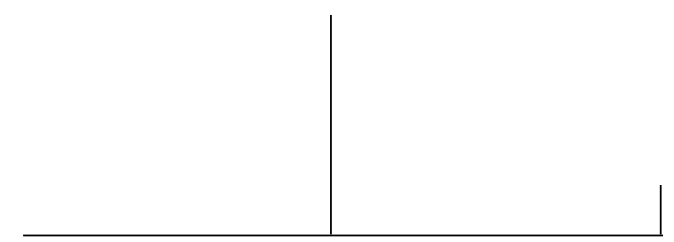

Rev. Latinoam. Psicopat. Fund., São Paulo, v. 15, n. 3, p. 459-463, setembro 2012

\title{
Editorial
}

\section{A questão da qualidade}

Manoel Tosta Berlinck

Diz-se que a qualidade da produção é o grande desafio que temos à nossa frente, como editores de periódicos e autores de artigos científicos.

O que significa, entretanto, um artigo de qualidade? Uma revista científica almeja, sempre, publicar artigos de qualidade. Mas a literatura sobre a qualidade é bastante escassa. Editores e autores estão preocupados com o plágio, a cópia de ideias sem a citação apropriada. Desenvolvem ferramentas para captar o plágio. Mas pouco, muito pouco mesmo, dizem sobre a originalidade ou sobre a qualidade.

A diferença entre um artigo de qualidade e um artigo original precisa ser reconhecida. Em outras palavras, um artigo original nem sempre é de qualidade, pois pode ser banal.

A originalidade ocorre quando ideias separadas são articuladas (Brito Cruz, 2011). Às vezes essas articulações são relevantes, outras vezes são banais. A busca pela originalidade pode nos afastar da qualidade. Entretanto, a ciência avança quando realiza articulação de ideias separadas.

No atual contexto, um artigo de qualidade é aquele que produz repercussão, medida, habitualmente, por um índice de impacto, referindo-se ao número de citações geradas. Artigos originais, quando são banais, não produzem índice de impacto. A banalidade, por sua vez, não se refere à repetição. A banalidade se opõe à 
relevância. Um artigo banal não tem importância, não é relevante e, por isso, não merece ser citado.

Sabe-se, entretanto, que nem sempre o índice de impacto é medida adequada nem de qualidade, nem de relevância. Assim, por exemplo, há artigos de qualidade que não produzem índice de impacto, a não ser muito tempo depois de terem sido publicados. Além disso, um autor não consegue escrever um artigo de impacto. Ele é capaz de escrever um artigo de qualidade. Ele pode, até, reconhecer a originalidade e a relevância de seu trabalho. Mas, o índice de impacto é uma consequência do artigo que pode ser de baixa qualidade ou de pouca originalidade. Por exemplo, artigos que tratam de assuntos controvertidos, frequentemente sem importância, atraem citações e possuem alto índice de impacto. O impacto é, pois, uma consequência, muitas vezes contingente, de um artigo científico. Ainda que o índice de impacto seja uma medida sobre o número de vezes que um artigo é citado, ele não é nem uma medida fidedigna nem válida para se determinar a qualidade de um artigo.

Neste sentido, a qualidade seria uma complexa propriedade intrínseca do artigo. A qualidade, por sua vez, refere-se a propriedades muitas vezes formais do artigo. Por exemplo, mesmo os detratores de Freud reconhecem que foi um grande escritor. Para ter qualidade, um artigo precisa ser claro, preciso, bem escrito e, portanto, compreensivo. Precisa, também, conter uma originalidade que proporcione ou estimule novas pesquisas.

O que faz com que um texto possua, então, uma longa duração? Se a qualidade for medida pela duração, ou seja, pelas citações ao longo do tempo, ela seria reconhecida pela influência que um texto exerce sobre o texto de outros autores.

A influência pode, entretanto, ser benéfica ou maléfica. Assim, por exemplo, o texto de Adolf Hitler, Minha luta, exerce uma influência considerada por muitos como maléfica. Por outro lado, o texto de Platão, O banquete, exerce uma influência considerada benéfica. Há que se pensar, então, sobre a natureza da influência de um texto quando se trata de sua qualidade.

Tanto o texto de Hitler quanto o de Platão orientam a ação e o pensamento. A influência é, aqui, a capacidade de orientar o pensamento de outros, além da do autor.

Na ciência, a influência é exercida por duas formas distintas sem serem mutuamente exclusivas.

Por um lado, textos que explicam a relação entre fenômenos são considerados influentes. A explicação se caracteriza por estabelecer uma relação causal, isto é, uma relação que trata do fazer acontecer algo. Um fenômeno é explicado quando digo como algo acontece. Por exemplo, a intoxicação ocorre quando um corpo vivo entra em contato com alguma substância tóxica.

Rev. Latinoam. Psicopat. Fund., São Paulo, v. 15, n. 3, p. 459-463, setembro 2012 


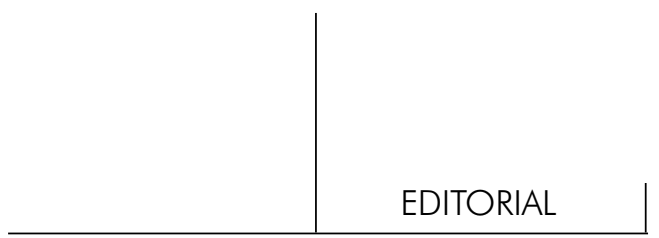

Substâncias tóxicas causam ou provocam intoxicação, ou seja, fazem com que a intoxicação ocorra. Essa relação causal é, entretanto, banal, do ponto de vista científico. Porém, ela pode estimular muitas pesquisas sobre a natureza tóxica de substâncias.

Por outro lado, a compreensão não está baseada na explicação. Ela está voltada para a revelação, o desvelamento da natureza de um dado fenômeno. Quando um texto permite a compreensão, ele estimula o leitor para um desvelamento, uma revelação e esta é outra forma de exercer influência. Assim, por exemplo, a compreensão sobre a queda da maçã de uma macieira carregada de frutos maduros não explica a queda da maçã, mas permite que haja uma compreensão, um entendimento sobre a queda da maçã. Assim, a Física é ciência que não explica a queda da maçã, ou seja, ela nada tem a dizer por que uma determinada maçã se desprende da macieira. Mas permite uma compreensão sobre a natureza da queda da maçã quando esta ocorre, ou seja, revela, desvenda o comportamento da maçã depois dela se desprender da macieira. A Física também nada tem a dizer por que Isaac Newton foi (supostamente) dormir debaixo de uma macieira. Essa seria uma questão relevante para a Psicopatologia Fundamental.

A influência de um texto científico, entretanto, não termina quando explica ou quando promove a compreensão de um fenômeno. Ela é reconhecida, também, por suas consequências em pensamentos de outros. Assim, por exemplo, a queda da maçã deu origem àquilo que denominamos a Mecânica, ou seja, uma compreensão ampla sobre o movimento dos corpos. Ora, se entendermos, como faz Aristóteles, que o movimento - anima - é o que caracteriza a vida, a Física seria a ciência dedicada à explicação e à compreensão da vida. Trata-se, portanto, de uma ciência de ampla influência e, nesse sentido, de grande relevância. Toda vez que quisermos explicar ou compreender a vida, ou seja, a animação, o movimento dos corpos, é aconselhável lançarmos mão da Física.

A Psicanálise, pretendendo ser uma ciência natural, como a Física, se ocupa do movimento psíquico (ou a falta deste). A sexualidade (e não o sexo) é a causa que permite a compreensão dos movimentos dos corpos vivos, proposta por Freud e seus associados.

A maçã freudiana é o caso clínico, fundamento para a compreensão sobre a natureza do psiquismo (Magtaz e Berlinck, 2012).

Assim como a Física tem, como fundamento da Mecânica, a queda da maçã que solicitou de Newton uma longa e complexa pesquisa, a Psicopatologia Fundamental tem o caso clínico como fundamento da pesquisa psicopatológica desde que se ocupe do obscuro enigmático, como ocorreu com Newton (Magtaz e Berlinck, 2012). Assim como Newton foi afetado - pelo menos é o que se diz - pela queda da maçã, o caso clínico afeta o clínico e estimula a produção do psicopatólogo, solicitando longas e complexas pesquisas sobre a natureza do 
pathos psíquico. É verdade, porém, que a Física conseguiu mensurar e quantificar os movimentos dos corpos enquanto que as intensidades e os movimentos do pathos psíquico ainda não foram quantificadas. Entretanto, os psicopatólogos se utilizam de modificadores de intensidades não quantitativos para se referirem a natureza do pathos. Usam, assim, expressões do tipo "muita", "pouca", "alta", "baixa" etc. Assim, diz-se que a Física é mais elegante que a Psicanálise, pois representa relações explicativas e compreensivas utilizando-se de uma linguagem mais precisa e clara.

Pode-se dizer, então, que a qualidade de um artigo depende da influência que exerce. Há, pois, na noção de qualidade, a noção de intensidade, ou seja, o poder para influenciar e movimentar o conhecimento. Um artigo de qualidade possui uma força, é forte e afeta quem o lê, provocando novas pesquisas.

Não basta, portanto, medir o número de citações de um artigo. A qualidade refere-se à potência, ou seja, a uma força que altera o estado de repouso ou de movimento constante e causa um deslocamento no sentido e na direção do conhecimento.

\section{Referências}

BRITo CRuz, C.H. Vannevar Bush: uma apresentação. Revista Latinoamericana de Psicopatologia Fundamental, v. 14, n. 1, p. 11-13, março de 2011.

Magtaz, A.C.; BerLincK, M.T. O caso clínico como fundamento da pesquisa em Psicopatologia Fundamental. Revista Latinoamericana de Psicopatologia Fundamental, v. 15, n. 1, p. 72-82, março de 2012.

\section{Manoel Tosta Berlinck}

Sociólogo; Psicanalista; Ph.D. (Cornell University, Ithaca, N.Y., USA); Professor da Escola de Administração de Empresas de São Paulo (EAESP) da Fundação Getúlio Vargas (1969-1972); Professor da Universidade Estadual de Campinas - Unicamp (Campinas, SP, Br.) (1972-1992); Sócio-fundador do Centro Brasileiro de Análise e Planejamento - Cebrap (1969- ); Diretor do Instituto de Filosofia e Ciências Humanas - IFCH da Unicamp (1972-1976); Professor do Departamento de Psicologia do Desenvolvimento da Faculdade de Ciências Humanas e da Saúde da Pontifícia Universidade Católica de São Paulo - PUC-SP (São Paulo, SP, Br); Professor do Programa de Estudos Pós-Graduados em Psicologia Clínica da Faculdade de Ciências Humanas e da Saúde da Pontifícia Universidade Católica de São Paulo - PUC-SP, onde dirige, desde 1995, o Laboratório de Psicopatologia Fundamental; Presidente 
da Associação Universitária de Pesquisa em Psicopatologia Fundamental - AUPPF (2002-2012); Editor responsável de Pulsional Revista de Psicanálise (1987-2009) e da Revista Latinoamericana de Psicopatologia Fundamental; Membro da World Association of Medical Editors - WAME (Associação Mundial de Editores Médicos) e do Council of Science Editors - CSE; Diretor da Livraria Pulsional - Centro de Psicanálise (1987-2009) e da Editora Escuta (1987-2009); Autor de Psicopatologia Fundamental (2000) e de Erotomania com German E. Berrios (2009), entre outros livros e numerosos artigos.

Rua Tupi, 397/103

01233-001 São Paulo, SP

Fonefax: 55113825.8573

e-mail:mtberlin@uol.com.br 